\title{
THE EFFECT OF ALLOYING ON Nb-SILICIDE PHASE STABILITY
}

\author{
B.P. Bewlay and K. Dovidenko
}

General Electric Global Research Center, Schenectady, New York 12301

Composites based on niobium solid solutions and niobium silicides, such as $\mathrm{Nb}_{5} \mathrm{Si}_{3}$ (tI32 crystal structure) and $\mathrm{Nb}_{3} \mathrm{Si}$ (tP32 crystal structure), are presently being developed for very hightemperature structural applications $[1,2]$. The use of alloying additions of elements such as Hf, $\mathrm{Ti}, \mathrm{Cr}$ and $\mathrm{Al}$ to improve composite properties has also been explored. The present paper describes the effect of alloying on the crystallography of $\mathrm{Nb}_{5} \mathrm{Si}_{3}$ and $\mathrm{Nb}_{3} \mathrm{Si}$ type phases. Microstructural analyses, electron backscatter diffraction pattern (EBSD), and X-ray diffraction data will be discussed.

$\mathrm{Nb}$-silicide in-situ composites typically form a niobium solid solution and $\mathrm{Nb}$-silicide phase on solidification $[1,2]$. The present paper will show that the crystallography of the $\mathrm{Nb}_{5} \mathrm{Si}_{3}$ phase that forms from the melt upon solidification is a function of the $\mathrm{Hf}$, $\mathrm{Ti}$, and $\mathrm{Al}$ concentrations in the Nb-silicide. The composites were prepared by arc melting and heat treatment, as described previously [1]. The cast composites were also hot isostatically pressed (HIP) and homogenized.

The composite microstructure and crystallography of the phases were examined both in the ascast, and the cast plus heat treated conditions. The microstructure of a cast $\mathrm{Nb}-24 \mathrm{Ti}-4 \mathrm{Hf}-5 \mathrm{Cr}-$ 2Al-2W-1.5Sn-14Si alloy is shown in Figure 1(a). The composite contained large-scale (Nb) dendrites $(\sim 75 \mu \mathrm{m})$ (light phase) that grew cooperatively with large-scale $(\mathrm{Nb})_{5} \mathrm{Si}_{3}$ (dark phase). The cooperative growth of the $(\mathrm{Nb})$ and $(\mathrm{Nb})_{5} \mathrm{Si}_{3}$ occurred in a cellular manner, and at the intercellular boundaries a eutectic of $(\mathrm{Nb})$ and $\mathrm{hP} 16(\mathrm{Nb})_{5} \mathrm{Si}_{3}$ was observed.

A similar microstructure was observed in the cast Nb-24Ti-4Hf-5Cr-2Al-2W-1.5Sn-20Si alloy as shown in Figure 1(b). However, a smaller volume fraction of $(\mathrm{Nb})$ dendrites was observed, and there was a larger volume fraction of $\mathrm{tI} 32(\mathrm{Nb})_{5} \mathrm{Si}_{3}$. EDS indicated that Hf partitioned strongly to the $h P 16(\mathrm{Nb})_{5} \mathrm{Si}_{3}$. Only a small volume fraction of $\mathrm{hP} 16(\mathrm{Nb})_{5} \mathrm{Si}_{3}$ was observed. The effect of additional alloying elements on the crystallography of the type $(\mathrm{Nb})_{5} \mathrm{Si}_{3}$ phases will also be described.

\section{References}

1. B.P. Bewlay, M.R. Jackson, and P.R. Subramanian, JOM, Vol 51(4) (1999), pp. 32-36.

2. M.G. Mendiratta and D.M. Dimiduk, Metall. Trans. Vol24A (1993), pp. 501-504. 

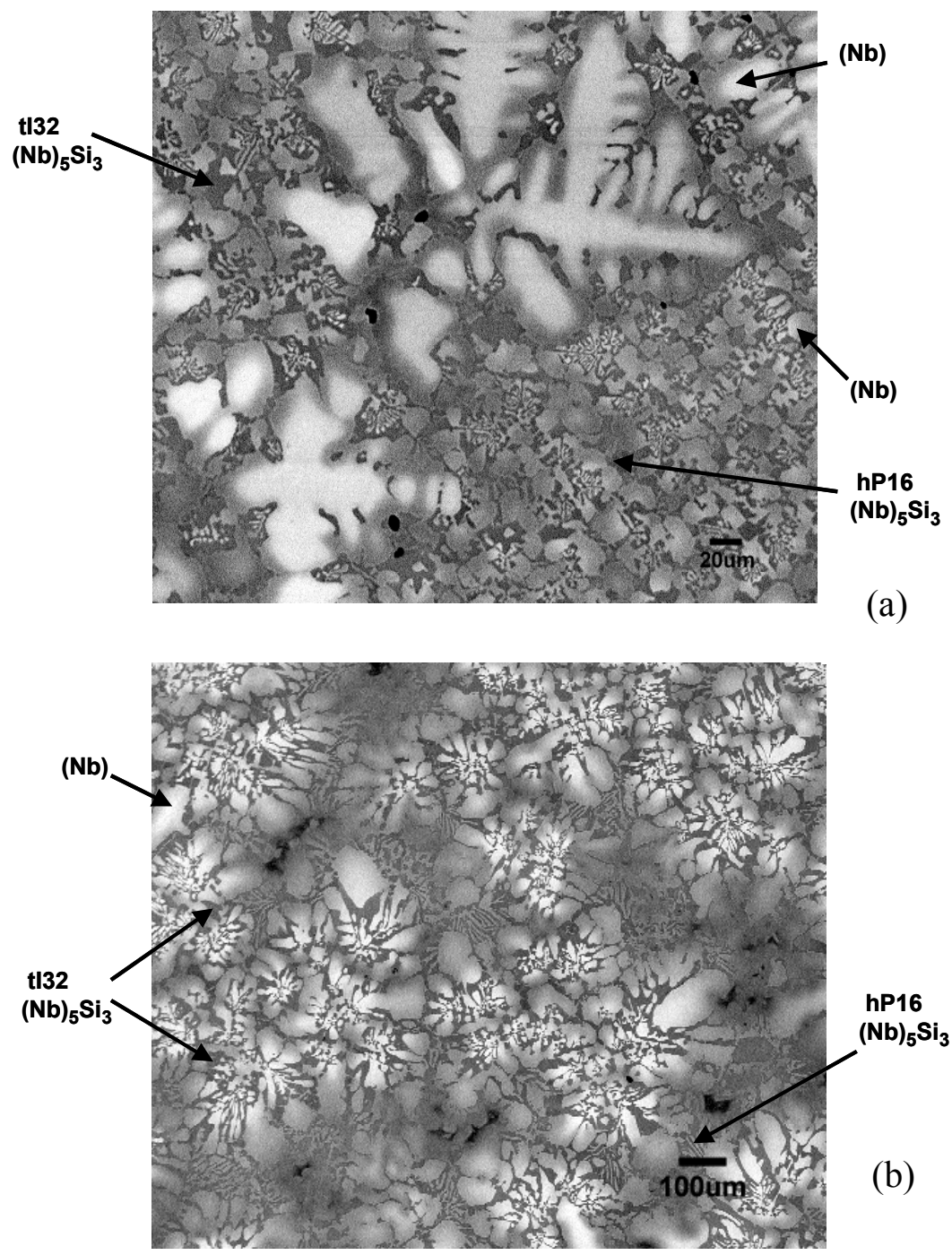

FIG. 1: Backscatter electron image (BSE) of the (a) Nb-24Ti-4Hf-5Cr-2Al-2W-1.5Sn14Si alloy, and (b) the Nb-24Ti-4Hf-5Cr-2Al-2W-1.5Sn-20Si alloy. 